Société d'histoire de la révolution de 1848 et des révolutions du XIXe siècle

$47 \mid 2013$

Quel est l'avenir du XIX $X^{\mathrm{e}}$ siècle ?

\title{
Matthieu BREJON DE LAVERGNÉE et Olivier TORT [dir.], L'union du Trône et de l'Autel ? Politique et religion sous la Restauration
}

Paris, Presses de l'Université Paris-Sorbonne, 2012, 252 p. ISBN :

978-2-84050-807-6. 18 euros.

Hélène Becquet

\section{(2) OpenEdition}

Journals

Édition électronique

URL : http://journals.openedition.org/rh19/4596

DOl : $10.4000 /$ rh 19.4596

ISSN : $1777-5329$

Éditeur

La Société de 1848

Édition imprimée

Date de publication : 31 décembre 2013

Pagination : 206-207

ISSN : 1265-1354

\section{Référence électronique}

Hélène Becquet, « Matthieu BREJON DE LAVERGNÉE et Olivier TORT [dir.], L'union du Trône et de l'Autel ? Politique et religion sous la Restauration », Revue d'histoire du XIXe siècle [En ligne], 47 | 2013, mis en ligne le 28 janvier 2014, consulté le 22 septembre 2020. URL : http://journals.openedition.org/ rh19/4596; DOI : https://doi.org/10.4000/rh19.4596 


\section{Matthieu BREJON DE LAVERGNÉE et Olivier TORT [dir.], L'union du Trône et de l'Autel ? Politique et religion sous la Restauration}

Paris, Presses de l'Université Paris-Sorbonne, 2012, 252 p. ISBN :

978-2-84050-807-6. 18 euros.

Hélène Becquet

\section{RÉFÉRENCE}

Matthieu BREJON DE LAVERGNÉE et Olivier TORT [dir.], L'union du Trône et de l'Autel ? Politique et religion sous la Restauration, Paris, Presses de l'Université Paris-Sorbonne, 2012, 252 p. ISBN : 978-2-84050-807-6. 18 euros.

1 Comme l'indique l'importante mise au point historiographique de Jacques-Olivier Boudon en introduction, l'ouvrage dirigé par Matthieu Brejon de Lavergnée et Olivier Tort s'inscrit dans le prolongement du renouveau historiographique actuel sur la Restauration. L'idée de regrouper des articles à l'articulation des histoires religieuse et politique de la période est d'autant plus intéressante que ce n'est pas le domaine dans lequel ce renouveau a été le plus marqué.

2 La première partie de l'ouvrage («La gestion publique des cultes: une adaptation continue ») concerne un aspect assez méconnu de la question religieuse sous la Restauration : la manière dont les cultes sont administrés. Jean-Pierre Moisset donne un aperçu du financement public des cultes, soulignant l'égalité matérielle entre protestantisme et catholicisme. Dans une perspective mêlant analyse politique et histoire administrative, Rémy Hême de Lacotte revient sur un épisode controversé de l'histoire de la Restauration: la création du ministère des Affaires ecclésiastiques. En démontant avec une grande précision les mécanismes et les enjeux de la naissance de 
cette institution inédite, il montre les tâtonnements, les tensions voire les impasses de la politique religieuse de la Restauration. Dans le dernier article de cette partie, Nadine Gastaldi s'intéresse à la place du judaïsme dans la politique des cultes de la Restauration à travers le cas de la création de l'École rabbinique de Metz en 1829.

3 La deuxième partie («Assumer le passé: querelles symboliques et conflits de mémoire ») regroupe quatre articles autour d'une problématique désormais classique sur la période. Thibaut Trétout choisit de se pencher sur une question de cérémonial en étudiant avec finesse les messes du Saint-Esprit qui avaient lieu la veille de l'ouverture des Chambres. Par la reprise de cette ancienne cérémonie, Louis XVIII et Charles X manifestent de manière éclatante la sacralité de la monarchie française en même temps qu'une certaine défiance pour la politique des hommes, bien éloignée du dessein divin. Emmanuel Fureix revient ensuite, dans un article dense et synthétique, sur le deuil « conflictuel » du régicide, qu'il a par ailleurs si bien éclairé dans son bel ouvrage $L a$ France des larmes ${ }^{1}$. Prenant le problème du lien entre monarchie et religion en creux, Paul Airiau s'intéresse aux faux Dauphins de la Restauration montrant que, contrairement à leurs successeurs de l'après 1830 , ils ne sont pas les détenteurs d'un discours providentiel, confisqué par le pouvoir royal. Enfin, Jean-Paul Clément revient sur la manière dont Chateaubriand envisage la place de l'Église dans la politique et la société de la Restauration.

4 La troisième partie, au titre quelque peu énigmatique («Peser sur le présent: échos d'une politique ambiguë»), est la moins cohérente du recueil : le point commun entre les différentes contributions n'apparaît pas de manière évidente. Pierre-Yves Kirschleger étudie les sermons publiés sous la Restauration, les considérant comme révélateurs des désirs et aspirations de protestants avant tout heureux de leur récente réintégration à la communauté nationale. Matthieu Brejon de Lavergnée traite pour sa part d'un tout autre aspect de la question en présentant la Société des bonnes études. Il offre un portrait de la jeunesse de droite, délaissée par l'historiographie, et complète heureusement notre connaissance des réseaux ultraroyalistes. L'article d'Olivier Tort concerne le discours sur la misère matérielle du clergé dans les chambres. Il démonte de manière convaincante le mécanisme en trompe-l'œil de cette rhétorique mise au service de combats politiques qui la dépassent largement et sans aucune efficacité réelle. Enfin, Séverine Blenner-Michel consacre un intéressant article à un groupe d'hommes de mauvaise réputation: les évêques de la Chambre des pairs, dont les opinions et les discours parfois divergents reflètent cependant un attachement profond à l'alliance du Trône et de l'Autel.

5 L'union du Trône et de l'Autel ? n'échappe pas à une certaine disparité de contenu entre les différents articles, défaut assez communément répandu dans le genre du recueil. Cette disparité est rendue plus flagrante encore par l'absence de conclusion à l'ouvrage. En outre, si la présence d'un cahier d'illustration, véritable luxe éditorial, est plaisante, l'iconographie ne concerne en rien le reste du recueil, ce qui est quelque peu gênant. Malgré tout, ce livre propose des perspectives de recherches et un bilan historiographique bienvenus. 


\section{NOTES}

1. Emmanuel Fureix, La France des larmes. Deuils politiques à l'âge romantique, Seyssel, Champ Vallon, 2009. 